\title{
COMPREENSÃO DAS FAMÍLIAS DE ÁREA DE OCUPAÇÃO IRREGULAR SOBRE O MEIO AMBIENTE E A SAÚDE AMBIENTAL
}

\author{
FAMILIES' COMPREHENSION ABOUT THE ENVIRONMENT AND AMBIENT RELATED \\ TO HEALTH WHO LIVE IN IRREGULAR OCCUPATION AREA \\ LA COMPRENSIÓN DE LAS FAMILIAS DEL ÁREA DE OCUPACIÓN IRREGULAR \\ SOBRE EL MEDIO AMBIENTE Y LA SALUD AMBIENTAL
}

\author{
Maria Glícia Rocha da Costa e Silva Noronha* \\ Maria de Lourdes Centa**
}

\begin{abstract}
* Enfermeira, Especialista em Saúde Coletiva: área de concentração em Saúde da Família. Mestranda em Tecnologia, Programa de Pós-graduação em Tecnologia - Universidade Tecnológica do Paraná (UTFPR). Membro do Grupo de Estudos Família, Saúde e Desenvolvimento (GEFASED).

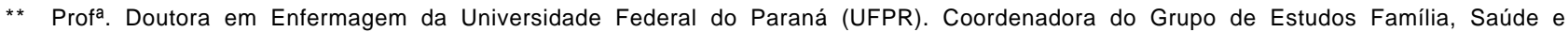
Desenvolvimento (GEFASED).
\end{abstract}

RESUMO. Este trabalho constitui-se numa pesquisa exploratória que utilizou o Discurso do Sujeito Coletivo, como caminho metodológico. Foi realizada junto a famílias de baixa renda, moradora de uma área de ocupação irregular, localizada num bairro de classe média da cidade de Curitiba, PR. Teve como objetivo a identificação da compreensão das famílias sobre o meio ambiente e a saúde ambiental. Utilizou-se para coletar dados um questionário com perguntas abertas e fechadas, anotação em caderno de campo e entrevistas gravadas. Seguiu a Resolução 196/96, Diretrizes e Normas Regulamentadora para Pesquisa com Seres humanos. Os dados obtidos foram agrupados em categorias e subcategorias denominadas respectivamente: CUIDANDO DE SUA MORADIA: ações de saneamento básico; cuidados com animais domésticos; combate a insetos e roedores. PRESERVANDO O AMBIENTE EM QUE VIVEM: evitando a poluição, preservando árvores e rios; fontes naturais de água, acondicionamento de resíduos. COMPREENDENDO O AMBIENTE EM QUE VIVEM: o que entendem por meio ambiente e saúde ambiental; riscos e impactos presentes no ambiente onde vivem. DEFENDENDO SEUS DIREITOS: mobilizações comunitária em defesa dos direitos comunitários e do ambiente, não disponibilização de informações e incentivo à cidadania. Concluiu-se que as famílias devem ser estimuladas e orientadas a preservar e cuidar do meio ambiente, exercendo sua cidadania junto aos órgãos competentes, para que eles implementem ações capazes de melhorar a qualidade ambiental e, com isso, proporcionar meios de vida saudável a seus habitantes.

PALAVRAS-CHAVE: família; meio ambiente; saúde.

ABSTRACT. This work consists in an exploratory research that used the Speech of the Collective Citizen, as methodological way. It was carried out with low income families, dwelling at middle class region of Curitiba city - Brazil. Its objective was to identify the families' comprehension about the environment and ambient related to health. A questionnaire with open and closed questions, notes in a field notebook and recorded interviews, was utilized to collect information. It obey the Regulatory Norms and Guide Lines of Research in Human Beings. The information was grouped in categories and subcategories respectively denominated: DOMICILE CARE: basic sanitation actions; domestic animals care; insects and rodent animals combat. PRESERVING THE ENVIRONMENT: to avoid pollution, to preserve trees, rivers and water source and to treat garbage. COMPREHENDING THE ENVIRONMENT: present doubts about the environment, the risks and the existing impacts in this environment. DEFENDING YOUR RIGHTS: communitarian mobilizations in defense of the environment, lack of information and citizenship incentive. It drove that families must be stimulated and instructed to preserve and take care of the environment, exercising its citizenship in partnership with public departments, in order to introduce actions to improve the ambient quality and, with this, provide healthy means of life to its inhabitants.

KEYWORDS: family; environment; health.

RESUMEN. Este trabajo consiste en una investigación exploradora, que utilizó el discurso del ciudadano colectivo, como manera metodológica. Fue realizado a través del acceso a familias de bajo ingreso, habitantes de una área de ocupación irregular, situada en un local de clase media de la ciudad de Curitiba, PR. Su objetivo era la identificación y comprensión de las familias sobre el ambiente y la salud ambiental. Fue utilizado para coger las informaciones un cuestionario con preguntas en abierto y cerradas, notas de cuaderno de campo y entrevistas gravadas. Se respeto la resolución 196/96, de normas reguladoras y directriz de la investigación con seres humanos. La información obtenida fue agrupada en clases y subclases denominadas respectivamente: CUIDADO DEL DOMICILIO: acciones básicas del saneamiento; cuidado de los animales domésticos; combate a los insectos y a los demás animales roedores. PRESERVAR LA VIDA EN EL AMBIENTE: evitando la contaminación, preservando los árboles y ríos; fuentes naturales, condicionamiento y residuos de agua. COMPRENDER LA VIDA EN EL AMBIENTE: dudas del momento sobre el ambiente, los riesgos y los impactos existentes en el ambiente construido. DEFENDER SUS DERECHOS: movilizaciones comunitarias en defensa de los derechos en común y del ambiente, escasez de información e incentivo a la ciudadanía. Se concluye que las familias deben ser estimuladas y orientadas al cuidado del local y del ambiente, ejercitando su ciudadanía frente a los departamentos competentes, de modo que estos realicen acciones capaces de mejoran la calidad ambiental y así proporcionar medios saludables de vida a sus habitantes.

PALABRAS-CLAVE: familia; ambiente; salud.

Recebido em: 15/03/2005

Aceito em: $\quad 09 / 08 / 2005$
Maria Glícia Rocha da Costa e Silva Noronha

Av. Manoel Ribas, 2727- 82400-000 - Curitiba - PR

Fone: (41) 3350-9272 - E-mail: glicianoronha@creapr.org.br 


\section{CONTEXTUALIZANDO O TEMA EM ESTUDO}

Partindo-se do paradigma do ambiente como determinante da saúde humana, a moradia (sua habitação) se constitui em um espaço de construção da saúde e consolidação do seu desenvolvimento. Neste contexto, as relações, interações e cuidado, que os indivíduos e suas famílias, mantêm no meio ambiente onde vivem, ou seja, no seu espaço de moradia e entorno, constituem-se em fator de promoção da saúde e qualidade de vida.

O conceito de meio ambiente e desenvolvimento humano*** passam pela construção de ações que carecem da consciência e responsabilidade social globalizadas, carregadas de ideologias e de historicidade. A perpetuação da espécie e o desenvolvimento humano, mantêm estreito relacionamento com o desenvolvimento sustentável da vida no planeta, pois o ser humano tem direito a vida saudável e sustentável. Para isso ele deve ter acesso aos recursos e às informações, que possibilitem melhorar sua condição de vida, suas relações sociais, ambientais e de saúde, além de seu viver em sociedade, principalmente a dos indivíduos de classes menos favorecidas ${ }^{1}$.

O baixo grau de percepção da população em relação aos problemas ambientais ${ }^{2 ; 3}$ pode ser explicado de muitas formas; uma delas é que, para algumas pessoas, falar de meio ambiente significa fundamentalmente falar da fauna e da flora, componentes do ambiente ao seu redor. Poucos são aqueles que incluem as cidades e os seres humanos como elementos que fazem parte do meio ambiente global. Percebe-se que alguns indivíduos se

*** O Programa das Nações Unidas para o Desenvolvimento (PNUD) desde 1990, enfatiza o Índice de Desenvolvimento Humano (IDH) como um índice do desempenho das políticas de desenvolvimento para além do comportamento aferido pelo Produto Interno Bruto. O IDH está baseado nos componentes: indicadores de longevidade, educação e renda per capita. Os conceitos de meio ambiente e desenvolvimento humano estão contemplados nos objetivos da Declaração do Milênio (2000 $\mathrm{ONU}$ ). Entretanto, segundo o atual relatório, o desenvolvimento humano não se esgota nestes 'Objetivos do Milênio', mas constitui-se em metas / referência crucial para uma nova ordem mundial, mais justa, menos pobre e menos insegura. Para atingilas, o mundo depende da cooperação internacional, uma cooperação sustentada nos pilares de ajuda dos países ricos aos em desenvolvimento; no estabelecimento de regras mais justas para o comércio internacional; e na ampliação do conceito de segurança, para além das fronteiras nacionais, com a redução dos conflitos armados nas regiões mais vulneráveis. PENUD, 2005. manifestam apenas como meros espectadores do meio ambiente, não partilhando dele e não compreendendo que suas ações e atitudes podem minimizar ou maximizar os danos e agravos à ele causados ${ }^{4}$.

Outra razão é que as marcas da pobreza e da marginalização são preconceitos que permeiam as famílias que compõem as camadas de baixa renda, moradores de áreas de ocupação irregular localizadas na periferia dos centros urbanos. Estas concepções estão presentes desde sua formação pessoal até sua forma de sobrevivência e são fatores que, em geral, levam à maior diferenciação dessas famílias e à falta de informação, atenção e cuidado ambiental. Todos estes fatores contribuem para o agravamento da saúde desses indivíduos e de suas famílias, bem como da saúde ambiental.

Isto tem sido bastante enfocado após a Declaração do Milênio, aprovada pelas Nações Unidas em 2000. Após esta declaração, todas as nações do planeta assumiram o compromisso para a erradicação da extrema pobreza e a fome até 2015 .

O meio ambiente passou a fazer parte das políticas pública no Brasil, a partir da década de noventa do século passado. Antes disso, o tema, sobretudo no que se refere à gestão dos bens ambientais por parte de Estados e Municípios, estava restrito à esfera técnica. Nos centros urbanos, o foco voltava-se ao controle da poluição industrial. Após a Conferência das Nações Unidas sobre Meio Ambiente e Desenvolvimento (Rio 92 ou Eco 92), a questão urbana e o meio ambiente se tornaram significativos. Os primeiros passos para a Agenda 21 passam a ser traçados, e surgem articulações entre movimentos sociais reivindicativos nas áreas urbanas e ambientalistas, que firmam encontros comuns, como questão emergencial a ser tratada ${ }^{5}$.

Entretanto sabe-se que a manutenção dos bens ambientais em um município é de natureza pública e demanda uma série de serviços permanentes. Neste sentido, a qualidade de vida dos habitantes das cidades depende, cada vez mais, de um arsenal de serviços que só tendem a crescer continuamente ${ }^{2 ; 3}$. 
De modo geral, espera-se que, na mesma medida, aumente a consciência ambiental média dos cidadãos, seu conhecimento sobre o meio ambiente construído e as implicações na qualidade de suas vidas.

Para intervir sobre os fatores determinantes da saúde-doença num espaço construído, torna-se necessária a articulação das políticas públicas, de habitação, saúde, meio ambiente e infra-estrutura urbana. Nestas, alguns fatores ambientais são eleitos como prioritários para identificar os problemas emergentes vivenciados pela população/comunidade de risco, voltados ao combate de doenças e enfermidade ${ }^{6 ; 7 ; 8}$.

De acordo com a Organização Pan-Americana de Saúde ${ }^{9}$, a idéia de municípios/ cidades saudáveis só é possível, se houver uma política de habitação saudável. A qualidade de vida dos indivíduos e de suas famílias, o desenvolvimento urbano e ambiental se insere na colaboração interprogramática em municípios/cidades saudáveis. Isto se torna efetivo, quando operacionalizadas por intermédio da elaboração de políticas públicas saudáveis, que exigem uma ação intersetorial e de nova institucionalidade social.

Tendo em vista as complexidades aqui envolvidas, necessitamos definir alguns conceitos. A partir destes, cumpre avaliar os riscos e situações encontradas. Entre os conceitos pertinentes, selecionou-se: atenção primária ambiental; vigilância ambiental em saúde; promoção da saúde; ambiente e entorno saudável e fatores de risco. Eles subsidiam avaliações das condições, estilo e qualidade de vida dos indivíduos e de suas famílias.

Atenção primária ambiental ${ }^{9 ; 10}$ são estratégias básicas de nível local, de participação da sociedade civil e das organizações locais por meio do conhecimento, identificação e solução dos problemas ambientais primários que atingem a saúde, limitando a qualidade de vida e o desenvolvimento sustentável. Compreende a educação ambiental; a contaminação simples dos ambientes de vida domiciliares e de trabalho; poluição sonora; qualidade e disponibilidade de água potável; controle de vetores transmissores de doenças, em combinação com a vigilância epidemiológica; manejo e reciclagem de resíduos sólidos; controle de qualidade de alimentos, em combinação com a vigilância sanitária; erosão de solos, queimadas florestais, pragas, urbanização de ruas, áreas verdes e outras 6;9;10

Vinculamos este conceito ao que entendemos por Saúde Ambiental. A nosso ver, os dois conceitos compõem a atenção primária, como ações ambientais preventiva e promocionais de saúde do indivíduo e do ambiente. Nestas ações, são reconhecidas os direitos dos indivíduos e de suas famílias a viverem em meio ambiente saudável, e a serem informados sobre os riscos ambientais em relação a sua saúde e bemestar ${ }^{10}$. Sob este enfoque, a vigilância ambiental em saúde, deve complementar o conjunto de abordagens em Atenção Primária Ambiental. Consideramos vigilância ambiental como um conjunto de ações, que proporcionam o conhecimento e a detecção de qualquer mudança nos fatores determinantes e condicionantes do meio ambiente que interferem na saúde humana, com a finalidade de recomendar e adotar as medidas de prevenção e controle dos fatores de riscos e das doenças ou agravos relacionados à variável ambiental ${ }^{11}$.

A Carta de Ottawa ${ }^{11}$, emitida na primeira Conferência Internacional sobre a Promoção da Saúde, realizada em Ottawa em 1986, estava dirigida para o objetivo "Saúde para Todos no Ano 2000". Esta carta define a Promoção da Saúde como o processo de capacitação da comunidade para atuar na melhoria da sua qualidade de vida e saúde, incluindo uma maior participação no controle deste processo na vida cotidiana das comunidades. A promoção da saúde, envolve diretamente o ambiente (suas moradias), onde vive os indivíduos e suas famílias e no qual os fatores de risco estão presentes ${ }^{11 ; 7}$. Por ambiente e entorno saudável, entende-se a incorporação das necessidades de ter equipamentos urbanos com saneamento básico, espaços físicos limpos e estruturalmente adequados, além de redes de apoio para se possibilitar hábitos psicossociais sãos e seguros, isentos de violência (abusos físicos, verbais e emocionais) ${ }^{8}$. 
Os fatores de risco, como 'sombras de causalidades' 8:810, têm a possibilidade de interferir nos sistemas vivos, psicossociais e do ser humano em seu funcionamento, com prejuízo para as condições individuais ou coletivas de saúde. Para análise destes fatores são considerados os aspectos: físicos, químicos, psicossociais, biológicos, socioeconômicos e sindrômicos 8;9. No campo da saúde coletiva, a ameaça ambiental está vinculada aos fatores de risco como determinantes dos processos de saúde-doença ${ }^{12}$. É o conceito da epidemiologia moderna, que procura determinar probabilisticamente a causalidade de determinados processos mórbidos.

A vida cotidiana dos sujeitos em família é entendida como processo em constante movimento, em que seus membros desenvolvem interações que vão construindo um universo específico em cada ambiente familiar ${ }^{13}$. A família, como instituição organizada da sociedade, passa a ser o lugar do sentido, do aprendizado e da compreensão da realidade vivida por cada indivíduo. Portanto é necessário, dentro da dimensão sociofamiliar, resgatar os valores e as relações que estruturam as famílias. Neste contexto, a informação e a educação formam o elo primordial para alicerçar o cuidado e o compartilhamento da vida familiar, envolvendo o ambiente que a cerca e de que ela faz parte.

Visto isto, a educação ambiental (EA) torna-se ferramenta importante, a ser implementada pelo governo local e sociedade, como estratégia para realizar uma atenção primária à saúde ambiental, enquanto prática, para a sustentabilidade: ela deve promover melhorias nas condições, estilo e qualidade de vida dos indivíduos e de suas famílias.

Neste enfoque, verificamos a necessidade da apropriação de conhecimentos para que possamos realizar exercício permanente de reflexão sobre nossas atitudes e ações, a fim de viabilizar mudanças e transformações em todos nós, em nossa interação com o meio. Para que este seja preservado, a população precisa estar bem fundamentada e motivada para exercer ações que o tornem saudável e sustentável, visto que somente a partir de informações, conhecimentos e motivação é que se opera a mudança de mentalidade em relação à necessidade de conservar o ambiente saudável para o bem das famílias que nele se inserem.

Para superar esta necessidade é necessário planejar e implementar programas de educação ambiental. Entende-se por educação Ambiental:

Os processos por meio dos quais o indivíduo e a coletividade constroem valores sociais, conhecimentos, habilidades, atitudes e competências voltadas para a conservação do meio ambiente, bem de uso comum do povo, essencial à sadia qualidade de vida e sua sustentabilidade (Lei $\mathrm{n}^{\circ}$ 9795 art. $1^{\circ}$ de 27/4/1999).

O direito de acesso à informação e participação comunitária, e aos bens e serviços para todos, e de um desenvolvimento sustentável, fortalece os pilares da construção da cidadania, tornando os indivíduos ainda mais presentes na tarefa de manter a 'Terra' como nossa morada temporária, mais saudável e aqui viver com qualidade ${ }^{14 ; 17}$.

Neste contexto, os problemas ambientais não se restringem apenas à proteção da vida, mas também à qualidade de vida. A injustiça social está relacionada diretamente ao modelo de desenvolvimento adotado. Assim, é urgente a necessidade da mudança de mentalidade, possibilitando transformar a consciência de toda a sociedade em direção à construção de um desenvolvimento humano e urbano que, para ser sustentável, precisa ser economicamente viável, sociocultural includente, eqüitativo e ecologicamente apropriado, possibilitando a todos um acesso respeitoso e sem discriminação de raça, cor, gênero, espécie.

É com este olhar, e reconhecendo nos indivíduos e em suas famílias o direito a viverem em um meio ambiente saudável, de serem informados sobre os riscos ambientais em relação à sua saúde e bem-estar, que realizamos este estudo. Assim, buscamos junto aos moradores de uma área de ocupação irregular identificar a compreensão que 
as famílias possuem do meio ambiente em que vivem e a saúde ambiental.

Para isto, procurou-se identificar, nas falas dos sujeitos envolvidos no estudo, a compreensão do meio ambiente e saúde ambiental, condições de vida, questões de saneamento básico e degradação ambiental do local em que vivem; identificar qual a visão destes sujeitos, sobre as intervenções e prioridades das políticas públicas governamentais municipais, oferecidas à comunidade local, pontuando os problemas referidos pelas famílias e coletividade, relacionados diretamente com a gestão do saneamento básico, saúde ambiental e os seus agravantes.

\section{CAMINHO METODOLÓGICO}

\section{DESCREVENDO A METODOLOGIA ESCOLHIDA}

A pesquisa constitui estudo exploratório qualitativo realizado com 58 famílias de baixa renda, moradoras de uma área de ocupação irregular, localizada num bairro de classe média da cidade de Curitiba, Paraná. O estudo teve seu foco na moradia, habitação ou domicílio familiar e em seu entorno, o meio ambiente. Buscou-se avaliar também a condição de vida e saúde das pessoas, como forma de intervenção e abordagem de educação em saúde e ambiental, auxiliando-as no resgate do direito de sua cidadania. A escolha das famílias foi realizada por sorteio aleatório do número de suas moradias, após mapeamento de toda a área de ocupação irregular, composta por 320 famílias, das quais selecionaramse 58 famílias para este estudo.

Para percorrer o caminho metodológico da pesquisa, foi escolhido o Discurso do Sujeito Coletivo (DSC) ${ }^{16}$, por possibilitar a pesquisa do 'pensamento coletivo'. Neste enfoque, a pesquisa das representações sociais, envolvendo a técnica do DSC, é qualitativa no sentido de que seu objeto - o pensamento coletivo - é composto de qualidades que os pesquisadores manifestam, desdobram e constroem, que aparecem como resultado do processo de pesquisa, alcançando-se a subjetividade humana.
De acordo com esta abordagem, somente dessa forma poderá ser dito que a coletividade tem um pensamento sobre dado tema, em que ela adota, professa ou usa um ou vários discursos sobre ele, captado durante o processo de investigação. Através da soma dos discursos coletados e captados na investigação, pode-se obter a descrição do pensamento coletivo num único discurso coletivo ${ }^{16}$.

O DSC ${ }^{16}$ é definido por seus autores como proposta de organização e tabulação de dados qualitativos de natureza verbal, obtidos nos depoimentos. Visa dar luz ao conjunto de individualidades semânticas componentes do imaginário social. Consiste em analisar o material verbal coletado, extraindo-se as idéias centrais, suas ancoragens e as suas correspondentes expressõeschave; a partir das expressões-chave das e idéias coletadas compõe-se um ou vários discursos-síntese na primeira pessoa do singular. É através do eu sintático, que sinaliza a presença de um sujeito individual do discurso, que se expressa uma referência coletiva na medida em que esse eu fala em nome de uma referência coletiva, que fala em nome de uma coletividade. Além dos depoimentos verbais, a pesquisa utilizou questionário com perguntas abertas e fechadas, para complementar os depoimentos e compor o Discurso do Sujeito Coletivo.

A coleta de dados foi realizada por meio de uma averiguação domiciliar, entrevistas e anotações em caderno de campo, aplicando-se um questionário com perguntas abertas e fechadas, que foram gravadas. As 58 famílias selecionadas consentiram em participar do estudo. Os dados coletados foram agrupados, seguindo indicadores pontuados nas entrevistas, mediante a freqüência com que estes indicadores surgiam nos discursos dos sujeitos pesquisados e optou-se por descrever o diagnóstico ambiental da estruturação atual na área de ocupação irregular, por meio do discurso das famílias. A abordagem dos sujeitos da pesquisa seguiu a Resolução 196/96 do Ministério da Saúde, Diretrizes e Normas Regulamentadora de Pesquisa com Seres Humanos ${ }^{15}$. 


\section{RESULTADOS E ANÁLISE DOS DADOS}

\section{CARACTERÍSTICA DAAMOSTRA}

Quanto ao perfil das famílias pesquisadas, das 58 famílias que constituíram a população amostra do estudo, 26 famílias possuíam 5 membros (entre membros nucleares e parentais); 15 famílias, com 4 membros; 8 famílias, possuíam 3 membros; 9 famílias, eram compostas de 2 membros, perfazendo um total geral de 232 pessoas componentes destas famílias. Das 232 pessoas que compõe estas famílias, 176 eram do sexo feminino e chefes de família, e 56 eram do sexo masculino. A renda familiar média das famílias era de 1 (um) salário mínimo ${ }^{\star * \star *}$, acrescidos de aquisição de cestas básicas, em 38 delas. O nível de escolaridade predominante era o ensino médio incompleto, seguindo-se do ensino fundamental completo, ensino médio completo e fundamental incompleto, todos estes distribuídos entre homens e mulheres. Vale ressaltar que, dentre as pessoas que integram as famílias abordadas, 129 são crianças de 1 a 4 anos, que não se encontravam em idade escolar, mas todas freqüentavam a creche pública da região.

Com relação à alimentação destas famílias, elas informam que fazem em média duas refeições ao dia, almoço e jantar, onde os alimentos predominantes são o arroz, feijão e ovo. De toda a amostra, apenas 44 famílias mencionaram comer carne e verduras 'quando tem' de uma a duas vezes por semana. Entretanto, quando se referem à alimentação das crianças, informam que, por elas estarem na creche, fazem as três refeições por dia.

Os recursos de apoio mais utilizados e relatados pelas famílias na comunidade como instrumentos de ajuda são a creche pública, Associação do Bairro e Igreja Protestante. A Unidade Básica de Saúde que atende essa área de abrangência também foi referenciada por quase todos os entrevistados devido especialmente ao trabalho desenvolvido pelo Agente Comunitário de Saúde da área. Isto fica claro no discurso abaixo:

valor correspondente ao salário mínimo na época da pesquisa era de $\mathrm{R} \$ 240,00$ (duzentos e quarenta reais).
Ela sempre está disponível quando precisamos... Quando alguém fica doente, ela está presente e procura resolver marcando consulta, arrumando remédio para quem precisa na Unidade de Saúde. Disto não se pode reclamar, pois o que depender dela, é feito mesmo. (DSC 1)

No que diz respeito à assistência realizada pela da Unidade de Saúde, diversos entrevistados referiram que ela não atende às necessidades das pessoas da comunidade, pois a procura por auxílio/assistência pelas famílias, na maioria das vezes, não é atendida.

Quanto às atividades de lazer praticadas na comunidade, predominam as brincadeiras de crianças na rua, e também em espaço de lazer, no centro de convivência, que pertence à escola pública do bairro .

\section{CATEGORIAS E SUBCATEGORIAS DA CONSTRUÇÃO DOS DISCURSOS DO SUJEITO COLETIVO}

Os dados obtidos depois de organizados e tabulados, nos possibilitaram compor os discursos coletivos através dos quais foram construídas as categorias e subcategorias denominadas. CUIDANDO DE SUA MORADIA: ações de saneamento básico; cuidados com os animais domésticos; combate a insetos e roedores. PRESERVANDO O AMBIENTE EM QUE VIVEM: preservando árvores e rios; fontes naturais de água; acondicionamento de resíduos. COMPREENDENDO O AMBIENTE EM QUE VIVEM: entendimento e dúvidas referentes ao meio ambiente; riscos e impactos existentes no ambiente. DEFENDENDO SEUS DIREITOS: mobilizações comunitária em defesa dos direitos comunitários e do ambiente; não disponibilização de informações e incentivo à cidadania.

Na categoria CUIDANDO DE SUA MORADIA e subcategorias, os participantes deste estudo informam a condição de suas moradias e ambientes circunvizinhos. Nesta categoria foram relatadas a oferta e existência de saneamento básico, como água, esgoto sanitário, coleta do lixo; o tipo de habitação, as condições de higiene da casa, ambiente peridomiciliar e circunvizinhos. No momento da coleta 
de dados, pôde-se observar que a condição das casas era muito precária; 30 moradias eram de madeira; 19 mistas (compostas de madeira e alvenaria), e 9 de alvenaria (destas, 5 sem acabamento externo e interno). Em geral, estas casas apresentam muita umidade, espaços escuros, ausências de janelas nos cômodos e algumas são conjugadas a outras.

Na subcategoria ações de saneamento básico observa-se que 54 das moradias possuem serviços de água tratada para consumo humano, providos pela rede pública - SANEPAR ${ }^{\star \star \star \star * ; ~} 26$ moradias possuem também poço manilhado nos fundos da casa. Todos os entrevistados informaram que na região existe 'uma mina de água' próxima de suas residências, e que a água é muito boa, melhor que da rede pública. Devido a constantes cortes e falta de abastecimento de água pela rede pública aos domicílios, em especial nos fins de semana, relatam que fazem consumo de água desta fonte e dos poços manilhados. Estes fatos, demonstram desinformação e falta de informação quanto à importância do uso de água tratada.

Quanto às instalações sanitárias (vaso sanitário), 35 moradias possuem instalações sanitárias em 'casinhas' fora de casa, e os dejetos humanos evacuados diretamente no córrego (valeta); em 21 moradias, os sanitários ficam dentro da casa, e 2 não possuem instalação sanitária, e nestas apenas 11 possuem fossa séptica para os dejetos humanos. Nas moradias restantes, os dejetos são também despejados diretamente no córrego ou quintal, a céu aberto. Nenhuma das 58 moradias conta com rede de esgoto tratado. Estes fatos são demonstrados nos discursos abaixo:

Eu tenho água da rede básica em casa, mas nos fins de semana temos sempre falta de água. Quando se consegue, armazenamos bastante água em baldes e vasilhas em casa, ou como cada um possa fazer.

**** A Companhia de Saneamento do Paraná - SANEPAR - foi criada em 1963 para cuidar das ações de saneamento básico em todo o Estado do Paraná. Os serviços de água tratada para consumo humano referem-se aos serviços providos pela Companhia de Saneamento do Estado do Paraná - SANEPAR - e que se destina aos serviços públicos de abastecimento de água, de coleta remocão e destinação de efluentes e resíduos sólidos domésticos e industriais, serviços relacionados a proteção do meio ambiente e aos recursos hídricos, dentre outros.
Poucos são aqueles que possuem ainda poço manilhado. Mas a maioria das pessoas pega água numa 'mina d'água' que temos aqui perto. Dá para pegar água para cozinhar, tomar banho, lavar roupa. (DSC 2)

Eu sei que faço errado, despejando os dejetos do vaso sanitário a céu aberto, ou seja, lá na valeta, mas não tenho alternativa diferente. Para fazer o certo, em primeiro lugar eu tinha que ter uma fossa, não tenho dinheiro para fazer uma fossa, pois custa caro. $E$ depois, ninguém tem acesso a esgoto tratado por aqui. Muito candidato, até candidato a governador já prometeu trazer esgoto para cá, mas não deu em nada. Agora, tem muitos moradores da região que não se importam mesmo com isso. Eles não sabem que as fezes sendo jogadas a céu aberto trazem doença. $E$ trazem doença para pessoas e animais, além de poluir tudo e ficar muito mau cheiro também. O que falta mesmo é educação para muita gente. (DSC 3)

$\mathrm{Na}$ subcategoria cuidados com os animais domésticos descreve-se que a maioria das moradias tem seu ambiente peridomiciliar (fundos da casa), margeado pelo Rio Wolf, atualmente se apresenta como um esgoto a céu aberto. No momento das entrevistas, observou-se a presença de animais domésticos (cachorro, gato, pato e galinha) soltos por toda a parte; nos relatos dos entrevistados não se percebe nenhum estranhamento das situações observadas, pois relatam que os animais ficam soltos e convivem com crianças e adultos, dentro e fora do ambiente familiar. A maioria dos entrevistados não informa iniciativas de vacinar os animais nem que Ihes tragam alguma doença. Isto demonstra falta de educação para a saúde na grande maioria dos entrevistados.

A maioria das pessoas da região tem muitos animais em casa como cachorro, gato, galinha, pato. E quase todos vivem soltos mesmo, pois é mais fácil de criar. Alguns animais, como cachorro e gato, dormem dentro de casa; essa região é fria mesmo, além de ajudar a vigiar a casa a noite. De dia ficam soltos na rua, no quintal. Só vacinamos os animais, quando a prefeitura faz campanha de vacinação de animais. Quando alguns animais ficam doentes, muita gente os solta na rua; outras vezes a carrocinha da prefeitura pega e leva não sei nem para onde. (DSC 4) 
$\mathrm{Na}$ subcategoria combate a insetos e roedores os entrevistados informam que existe nos domicílios presença de ratos, ratazanas, baratas, pulgas, pernilongos, morcegos, aracnídeos, principalmente as aranhas marrons. Esta informação foi relatada por todos os entrevistados. Não sabem o que podem fazer para conter a disseminação, pois realizar desinsetização custa caro para o padrão econômico dos moradores da região. De vez em quando conseguem da prefeitura uma desinsetização, principalmente no período das chuvas, quando ocorre enchente e o rio alaga as casas.

$\mathrm{Na}$ categoria PRESERVANDO O AMBIENTE EM QUE VIVEM e subcategorias, procurou-se compilar os discursos que refletem a preservação do meio ambiente, árvores, rios destino dado ao lixo, acondicionamento e sobre as fontes naturais de água. Nestes discursos os entrevistados demonstram 0 descaso do poder público para com o rio e desconhecimento de alguns moradores com a preservação do meio ambiente, das árvores, rios e fontes de águas naturais; Refere-se ainda como as famílias acondicionam e destinam os resíduos sólidos e dejetos humanos que produzem. Na subcategoria preservando árvores e rios os entrevistados relataram que no rio (valeta) é jogado todo tipo de resíduo e lixo, desde papelão, plástico, eletrodoméstico quebrado e velho, móveis, fezes, animais mortos, esgoto e água de fábricas, óleo diesel, tinta, pneus. É o que observamos no discurso a seguir:

O rio há muito tempo acabou, pois as suas águas recebem todo tipo de resíduos líquidos e sólidos: é esgoto doméstico canalizado desaguando diretamente dentro da valeta, ou até mesmos as 'casinhas sanitárias' são construídas diretamente sobre o rio; além de resíduos sólidos de todo tipo, encontramos papéis, garrafas plásticas, eletrodoméstico e até mesmo móveis, pois até sofá foi encontrado há poucos dias. E segundo me contaram, já foi descartado nas águas do rio uma sucata de carro velho, um tempo atrás. (DSC 5)

Quando mais pessoas começaram chegar nesta região, eles desmataram uma área enorme perto do rio e construíram suas casas com a própria madeira das árvores derrubadas. As casas foram se amontoando, as árvores cortadas e os animais silvestres foram desaparecendo, sendo substituídos por ratos, ratazanas, cães e gatos de rua, insetos como borrachudos, pulgas e aranhas marrons, que encontramos em todo o canto por aqui. Só tem árvore no outro lado do rio, que é um terreno particular. Não sobrou nada deste lado de cá. $\mathrm{Na}$ minha opinião poucas pessoas sabem preservar aqui. (DSC 6)

Muita coisa contamina os rios. O esgoto doméstico é a pior fonte desta contaminação, pois as fossas são despejadas diretamente em vala a céu aberto. Outra forma de contaminação do rio é jogar bicho morto em suas águas. Além disso, o rio recebe outros tipos de lixo, como o esgoto e água das fábricas, óleo diesel de oficina, graxa, tinta e pneu, garrafas, sacos plásticos e papel. Acho que muita coisa pode contaminar os rios, mas o principal é o lixo que se joga nele. Eu já ouvi dizerem na televisão que foi jogado lixo hospitalar em rios pela cidade. (DSC 7)

Discursos que se destacaram pela falta de informação dos moradores e o descaso do poder público.

A contaminação começa com o ser humano que descarta nos rios o que não necessita. Mas se lixo for jogado em local impróprio, inadequado, polui e contamina o meio ambiente.causa destruição da natureza, muita coisa de ruim acontece. As pessoas ficam doentes, pois o lixo traz doenças. Eu confesso que algumas vezes joguei lixo no rio. Eu acho que o lixo polui os rios sim, mas não sei bem o que fazer com o lixo. Acredito que o lixo é prejudicial ao meio ambiente e que a CAVO ${ }^{\star \star \star \star * *}$ leva para o local certo. (DSC 8)

$\mathrm{Na}$ subcategoria fontes naturais de água quanto às fontes de água natural, alguns entrevistados referem ainda consumir água delas, principalmente devido às freqüentes faltas no abastecimento de água pela Sanepar.

\footnotetext{
****** CAVO - Empresa que realiza prestação de serviços de limpeza urbana e saneamento da cidade de Curitiba/PR.
} 
Nós tínhamos nessa região várias nascentes ou mina d'água. Depois que a ocupação aumentou, a prefeitura fechou quase todas elas; existe uma fechada no final de minha rua. As que ainda temos ficam no local do antigo 'Seminário dos Padres'; têm uma nascente de águas límpidas, e uma outra no final da atual rua Alfredo Muraro. Eu não tenho poço manilhado em casa; quando a água da rede pública falta, uso dessa água para cozinhar e lavar roupa, pois a água é bem limpa. (DSC 9)

$\mathrm{Na}$ subcategoria acondicionamento de resíduos os entrevistados informam que a coleta de lixo orgânico é realizada pela prefeitura, acontecendo três vezes por semana; os coletores fazem a coleta de forma apressada; muitas vezes não recolhem todo o lixo, deixando alguns pacotes e lixo cair pelo chão, pois os sacos e caixas rasgam, ficando lixo espalhado na rua.

Dos participantes deste estudo, trinta e quatro entrevistados informaram que fazem a troca de alguns tipos de lixo reciclável por alimentos, junto a uma associação que pertence ao bairro vizinho. Durante a coleta de dados, observou-se que a maioria das famílias convive com o lixo no ambiente peridomiciliar jogado a céu aberto no quintal, onde também possuem vários animais domésticos, como cachorros, galinhas, patos, gatos. Observou-se lixo também em diversas áreas da região principalmente nas margens e dentro do córrego. Dos discursos que abordam estas questões, destacamos aqueles que fazem a diferenciação entre lixo de materiais considerados não lixo.

O lixo são as coisas que não podem mais ser aproveitadas, tais como: resto de comida, cascas de alimentos, pó de café, erva-mate, chimarrão, absorvente, embalagens, papel higiênico, fezes de animais, papel sujo, bituca de cigarro, papel higiênico, lata, plástico resíduo. Além disso tudo que não pode ser mais usado, reciclado, e aproveitado, é jogado fora. (DSC 10)

Discurso enfatizando a separação adequada do lixo orgânico, lixo tóxico e materiais recicláveis e reaproveitáveis.

Eu separo o lixo orgânico do lixo que é reciclável. Separo como lixo que não é lixo as garrafas descartáveis, caixas de leite, litros, latas, vidros, papel, plástico, papelão, caixas de sabão, papel, vidro, latas, plástico, lâmpadas florescentes e leva na rua da cidadania. No lixo comum coloco os restos da minha casa, papel higiênico e lixo da cozinha. As folhas e resto de vegetal, enterro. (DSC 11)

Na minha rua o carro da coleta de lixo comum da prefeitura passa duas vezes na semana e acho que a CAVO leva para o lugar certo. O que eu acho errado é que muitas vezes os empregados da prefeitura, ao pegar nas sacolas de lixo, os sacos rasgam e espalham todo o lixo na rua, pois eles passam sempre correndo pela rua. Agora o lixo que não é lixo, e também o comum, muitas pessoas moradores daqui recolhem toda tarde e levam para suas casas e depois vendem. Ultimamente o carro do lixo que não é lixo passa muito pouco, pois foi pedido na prefeitura para deixar esse material para as famílias que já fazem essa coleta aqui e vendem. (DSC 12)

\section{Na categoria COMPREENDENDO O AMBIENTE} EM QUE VIVEM, e sub categorias, encontramos o que segue. Na subcategoria o que entendem sobre meio ambiente e saúde ambiental os entrevistados relatam o que entendem por meio ambiente e saúde ambiental. Para eles a saúde ambiental é manter a casa e ambiente peridomiciliar limpos, ter cuidado com o lixo, animais, evitar poluição, possuir ar puro, plantas, conservar água de qualidade. Eles referemse também à falta de preocupação dos governos em promover e preservar a saúde ambiental.

Eu acho que saúde ambiental está relacionada com os cuidados com a casa e o quintal limpos, como também as árvores e os rios... É ar puro, é ter florestas conservadas, é incentivar crianças a plantar arvores... É separar bem o lixo que produzimos no dia a dia, evitando insetos, moscas, ratos... É manter as crianças longe das fezes de cachorros. (DSC 13)

Vejo muito falar de ecologia na TV, mas parece que o governo não está preocupado com as florestas dentro das cidades, pois os rios estão cheios de lixo, fezes, esgotos a céu aberto, não cuidam das ruas que têm terrenos com lixo e lixões... e outras coisas.... (DSC 14) Na minha opinião, falar sobre 'Saúde do ambiente' é falar sobre ter água boa para beber, ar puro para respirar, é manter a poluição longe de nossas casas, 
não deixar fazer queimadas, viver afastado de fumaça de fabricas... Isto sim é ter um ambiente com saúde. (DSC 15)

Nestes discursos percebemos o que compreendem por ambiente, sua degradação e poluição.

Para mim, o meio ambiente é o mundo a nosso redor, e fazem parte dele pessoas, rios, mares, árvores, animais, florestas. É tudo o que faz parte de nossa vida. É o meio onde moro e vivo. Tudo o que me cerca. Tudo o que tem vida. (DSC 16)

Eu acho que o meio ambiente fica doente porque é vivo. Parece que são humanos como nós, porque também se ressentem, e adoecem como as pessoas. Quando as árvores ficam sem água, elas ficam tristes e doentes. É igual quando as crianças tomam água suja e poluída, adoecem. Acho até que o meio ambiente fica doente até mais rápido que a gente, pois ele vive do oxigênio como nós. Se nós evitamos a poluição, com certeza teremos mais oxigênio para todos, para nós e para o meio ambiente. (DSC 17)

O meio ambiente adoece porque temos muita falta de cuidado com tudo a nosso redor. O próprio homem destrói o meio, cortando as matas como está acontecendo aqui perto. Essa ainda é uma prática muito comum; isto provoca a morte de animais e pássaros. Depois de cortar, fazem queimadas, jogam fumaça no ar. Outras formas do meio ambiente adoecer é quando não fazemos o controle do lixo que produzimos em casa, favorecendo a contaminação e entupindo bueiros e valetas, além de poluir as nascentes dos rios ou quando soltamos água com sabão e esgoto direto nos rios. Com tudo isso o meio ambiente fica doente. (DSC 18)

\section{A subcategoria riscos e impactos presentes} no ambiente onde vivem refere-se aos riscos, a saúde da comunidade e do meio ambiente. Nesta subcategoria optou-se por descrever as observações percebidas durante a coleta de dados, pois nas entrevistas pouco foi relatado pelos moradores. Entendemos que este fato se deveu à precariedade das condições de moradia em que se encontram, não sendo possível eles mesmos perceberem os riscos que correm. Entretanto os entrevistados, moradores mais antigos da área, referem que as moradias instaladas mais recentemente invadiram grande parte do leito do rio. Confirmamos esta informação durante a realização da coleta de dados. Observou-se diversas casas em palafitas de madeira sobre o rio, e outras, muito próximas as margens deste.

Constatou-se que a proximidade das moradias com o leito do rio contaminado constitui fator de risco para a saúde das famílias. Entre estes fatores, destacam-se: a) ocorrência freqüente de enchentes, principalmente durante as chuvas de verão; b) o consumo de água de 'fontes de água naturais' coletadas por moradores, devido a freqüentes faltas no abastecimento de água para consumo humano providos pela SANEPAR; c) o fácil acesso das pessoas à água do rio contaminado favorece a incidência de doenças veiculadas pela água, além do aparecimento de enfermidades, como doenças diarréicas, respiratórias, de pele e couro cabeludo; d) o lixo depositado em suas margens favorece a presença de ratos, ratazanas, baratas, moscas, pernilongos, aranhas marrons, morcegos, entre outros insetos, roedores e animais silvestres.

Outro fato observado é que as moradias possuem poucas janelas, luminosidade e ventilação, tornando os ambientes úmidos e insalubres; além disso, os cômodos são pequenos e co-habitados por animais domésticos. Alguns moradores colocam botijões de gás dentro do ambiente domiciliar, mesmo em quartos de dormir, fato que aumenta a probabilidade de ocorrência de explosões e incêndios. De modo geral, as instalações elétricas das casas são precárias e sua fiação encontra-se exposta, favorecendo incêndios e acidente doméstico com energia elétrica. As famílias coletoras de material reciclável, abrigam diversos tipos de lixo em suas moradias, seja no ambiente domiciliar como peridomiciliar. Outro agravante observado é a convivência diária com violência, droga e prostituição.

$\mathrm{Na}$ última categoria DEFENDENDO SEUS DIREITOS, e subcategorias, os entrevistados se referem sobre as mobilizações comunitárias já realizadas junto aos órgãos públicos, e também a carências de informações para preservação do meio ambiente e manutenção da saúde ambiental. 
$\mathrm{Na}$ subcategoria mobilizações comunitária em defesa dos direitos comunitários e do ambiente percebemos que os entrevistados manifestaram interesse em realizar mobilizações para recuperar o ambiente onde vivem, participando de ações coletivas neste sentido. Percebe-se nos discursos que eles continuamente fazem reclamações quanto à 'falta de manilhamento do córrego' e do esgoto a céu aberto. Reclamam também do mau cheiro, da presença de ratos, ratazanas, e informam que já fizeram diversos abaixo-assinados, solicitando providências junto ao Agente Comunitário de Saúde (ACS), mas que até o momento não conseguiram nenhum retorno do governo municipal. Eles informam que durante o período das chuvas, todas as moradias localizadas mais próximas do córrego, enfrentam as enchentes do "riozinho", pois a água invade casas e ruas, trazendo muito lixo, ratos, e doenças.

No período das chuvas é muito comum, as casas serem alagadas pelo rio que volta a ocupar o lugar dele. Como as casas foram construídas sobre o leito dele, a água invade e traz muito lixo, aparecem os ratos e muita sujeira. (DSC 19)

Eu moro nesta área há muitos anos. E quando cheguei aqui, o que se vê hoje como esgoto era um rio e passavam águas bem limpas. Hoje, o que vemos e sentimos é muito mau cheiro, a qualquer hora do dia e da noite. Para resolver esse problema, já fizemos muitos 'abaixo-assinado', alguns com mais cem assinaturas, pedindo providências à prefeitura. $O$ agente comunitário de nossa região tem muito interesse em nos ajudar a resolver todos esses problemas, Ela conhece nossa situação, pois mora bem perto daqui. Ela já colheu muitos abaixo assinados de todos aqui. Entregamos estes abaixoassinados na Rua da Cidadania, para vereadores do bairro e nunca deu em nada! Mas quem pode fazer alguma coisa por nossa localidade, não faz nada!. Nós todos já participamos de muitos mutirões organizados pelo agente comunitário, para a limpeza de toda a área, das ruas, recolhendo lixo a céu aberto e do córrego desta região toda. Mas pouco tempo depois, tudo volta a ficar sujo novamente. É uma pena, mas as pessoas não têm educação. (DSC 20)
A subcategoria não disponibilização de informações e incentivo a cidadania está bem representada com o discurso que segue.

A gente sabe que muitas pessoas precisam de informação sobre como jogar fora as coisas, o lixo, por exemplo, ou ainda, como melhor cuidar dos arredores da casa, como cuidar para não sujar o rio e o ambiente. A grande maioria das pessoas não sabe que, se cada um fizesse sua parte, muita coisa podia melhorar nossa vida. E dessa forma ficam sempre esperando que o governo tome as providências, não fazem". a sua parte, deixam para o governo fazer, ou que caia do céu. (DSC 21)

As situações acima expostas destacadas como riscos à saúde da comunidade e do meio ambiente, encontram-se contrárias ao preconizado pela Organização Pan-Americana de Saúde ${ }^{8}$, que traz na pauta das políticas em prol de habitação saudáveis para municípios/cidades saudáveis, intervenções sobre os fatores determinantes de saúde-doença em seu espaço construído, referenciado em diversos estudos. ${ }^{5-7 ; 10 .}$

Todos esses fatores acarretam danos à qualidade de vida das famílias que, em conseqüência, 'deságuam' no meio ambiente, como resultados, danos e conseqüências dos vivenciados no cotidiano. Percebemos desta forma a importância de articulação das políticas públicas de habitação com a saúde, o meio ambiente e a infra-estrutura urbana, em prol da promoção da saúde e qualidade de vida das famílias e comunidades.

\section{ALGUMAS CONSIDERAÇÕES FINAIS}

A sensibilização e a conscientização dos que habitam as áreas urbanas, em face dos desafios e resolução dos impasses do progresso da humanidade, reivindicam a integração entre homem e natureza. Precisa-se de política realmente redefinida e complementada por nós mesmos, pois o futuro só será escrito, quando o homem não mais se sentir como ser inócuo ante suas próprias ações. O entendimento do homem, como pertencente ao meio 
ambiente, e como principal ator e responsável no processo de sua manipulação, alterando-lhe as condições da flora, fauna e da sua própria vida, no presente, como também na vida das gerações futuras, se constituí na principal prerrogativa de se poder acreditar que um futuro para a vida na Terra, se torna essencial.

Entretanto compreendemos que, para se promover a sustentabilidade urbana, importa primeiro conhecer (fazer diagnósticos) e, depois, formular e propor políticas públicas com estratégias claras e viáveis, envolvendo a participação de todos os atores sociais presentes, a comunidade no seu cotidiano e mundo vivido e o poder público local.

Perante os dados encontrados nos discursos deste estudo, percebeu-se que as famílias possuem pouco conhecimento e informação sobre os cuidados com a saúde pessoal e do meio ambiente, devido às condições em que se encontram e vivem. Consideramos ser imprescindível que as famílias sejam estimuladas e orientadas a preservar e cuidar do meio ambiente, exercendo sua cidadania junto aos órgãos competentes, para que eles implementem ações capazes de melhorar a qualidade ambiental e, com isso, proporcionar meios de vida saudável a seus habitantes.

Finalmente salientamos a necessidade premente de buscar estratégias que conduzam a um convívio harmonioso com os componentes abióticos e bióticos do ecossistema, obviamente em consonância com os anseios de um desenvolvimento sustentável.

\section{REFERÊNCIAS}

1 Leff E. Saber ambiental: sustentabilidade, racionalidade, complexidade, poder. Petrópolis: Vozes; 2001.

2 Sorrentino M. Desenvolvimento sustentável e participação. In: Loureiro CFB. et al., organizadores. Educação ambiental: repensando o espaço da cidadania. São Paulo: Cortes; 2002. p.15-22.

3 Branco SM. Meio ambiente: uma questão moral, São Paulo. OAK; 2002. p. 224.
4 Zanonni M, Raynaut C. Sociedade, desenvolvimento, meio ambiente. Cadernos de desenvolvimento e meio ambiente n.1. Curitiba: UFPR; 1994.

5 Adams BG. A Carta da Terra Comentada II - com sugestões para trabalhos com crianças. Preâmbulo. Modulo I, UNESCO; 2003.

6 Buss PM et al. Promoção da saúde e saúde pública. Rio de Janeiro: ENSP;1998.

7 Buss PM. Qualidade de vida e saúde. Rev Abrasco 2000; 5(1).

8 Cohen SC et al. Habitação saudável no SUS. Uma estratégia de ação para o PSF: uma incorporação do conceito de habitação saudável na política pública de saúde. Documento produzido pela Rede Brasileira de Habitação Saudável. ENSP: Rio de Janeiro; 2003. p. 807-13. Disponível em: <http://www.abrasco.org.br/ gts/gt/promocao/habitacao saudável/psf.pdf>

9 OPAS. Guias Metodológicos para iniciativa de vivienda saludable; 2000. Disponível em:< www.cepis.ops-oms.org>

10 Teixeira MB. Atenção primária ambiental: o foco na experiência local. Debates Sócio-Ambientais 1997; 3(8):6-7.

11 OMS. Promoción de la salud carta de ottawa - glosario. OMS. Genebra; 1998. Disponível em: <www.who.org> (2 fev 2006).

12 Augusto LGS, Freitas CM, Torres JPM. Risco ambiental e contextos vulneráveis: implicação para a vigilância a saúde. Informe epidemiológico do SUS 2002; 11(3):155-8.

13 Centa ML. A família enfrentando a infertilidade. In: Elsen I, Marcon SS, Silva MRS, organizadores. O viver em família e sua interface com a saúde e a doença. Maringá: Eduem; 2002.

14 Boff L. Saber cuidar: ética do humano - compaixão pela terra. Petrópolis: Vozes; 1999.

15 Ministério da saúde (BR). Conselho nacional de saúde. Resolução no 196 - sobre pesquisa com Seres Humanos; Brasilia; 1996.

16 Lefévre F, Lefévre AMC. O Discurso do sujeito coletivo: um novo enfoque em pesquisa qualitativa (desdobramentos) /Lefèvre F, Lefèvre AMC/ Ed.rev. e ampliada, Caxias do Sul: Educs; 2003.

17 Boff L. A teologia da libertação como uma prática pedagógica; 2002. Entrevista retirada do site: <http://www.folhadirigida.com.br/professor/Cad03/ EntLeonardoBoff.html> 